\title{
Prevalence of Anemia and Associated Factors among Pregnant Women in an Urban Area of Eastern Ethiopia
}

\author{
Kefyalew Addis Alene ${ }^{1}$ and Abdulahi Mohamed Dohe ${ }^{2}$ \\ ${ }^{1}$ Institute of Public Health, College of Medicine and Health Sciences, University of Gondar, P.O. Box 196, Gondar, Ethiopia \\ ${ }^{2}$ Somali Regional Health Bureau, P.O. Box 238, Jijiga, Ethiopia \\ Correspondence should be addressed to Kefyalew Addis Alene; kefadis@gmail.com
}

Received 9 April 2014; Revised 26 July 2014; Accepted 2 August 2014; Published 25 August 2014

Academic Editor: Bruno Annibale

Copyright (c) $2014 \mathrm{~K}$. Addis Alene and A. Mohamed Dohe. This is an open access article distributed under the Creative Commons Attribution License, which permits unrestricted use, distribution, and reproduction in any medium, provided the original work is properly cited.

\begin{abstract}
This research work presents the magnitude of anemia and its determinant factors among pregnant women. As far as this research is done in the eastern part of Ethiopia, where there is a different cultural issue related to pregnancy and dietary habit, it will help the researchers to know the problem in different parts of the country.
\end{abstract}

\section{Background}

Anemia, defined as a decreased concentration of blood hemoglobin, is one of the most common nutritional deficiency diseases observed globally and affects more than a quarter of the world's population [1-8]. It is a major public health problem affecting all ages of the population with its highest prevalence among children under five years of age and pregnant women $[2,3]$. Globally, anemia affects 1.62 billion people (25\%), among which 56 million are pregnant women $[1,2]$.

Anemia during pregnancy is considered severe when hemoglobin concentration is less than $7.0 \mathrm{~g} / \mathrm{dL}$, moderate when hemoglobin falls between 7.0-9.9 g/dL, and mild from $10.0-11 \mathrm{~g} / \mathrm{dL}[2-4]$. Anemia during pregnancy is a major cause of morbidity and mortality of pregnant women in developing countries and has both maternal and fetal consequences [913]. It is estimated that anemia causes more than 115,000 maternal and 591,000 perinatal deaths globally per year [3].

In developing countries, the cause of anemia during pregnancy is multifactorial and includes nutritional deficiencies of iron, folate, and vitamin B12 and also parasitic diseases, such as malaria and hookworm. The relative contribution of each of these factors to anemia during pregnancy varies greatly by geographical location, season, and dietary practice. In Sub-Saharan Africa, iron and folate deficiencies are the most common causes of anemia in pregnant women [14]. Anemia has a variety of converging contributing factors including nutritional, genetic, and infectious disease factors; however, iron deficiency is the cause of $75 \%$ of anemia cases $[2,5,8-15]$. Iron deficiency anemia affects the development of the nation by decreasing the cognitive development of children and productivity of adults $[2,10]$.

Seventeen percent of Ethiopian women in the reproductive age group are anemic and $22 \%$ of these women are currently pregnant [16]. Despite its known effect on the population, there is very little data available in the study area. Therefore, this study is aimed at determining the prevalence of anemia in pregnant women and identifying its associated factors in the Somali Region of Eastern Ethiopia.

\section{Methods}

2.1. Study Setting and Design. A community based crosssectional study was conducted from April to May 2013 in Gode town, Eastern Ethiopia.

2.2. Study Population. The study population consisted of a sample of pregnant women who were residing in the town during the study period. Those pregnant women who were 
not long-term residents of the city (less than 6 months) were excluded.

2.3. Sampling Procedures. Sample size was determined based on single population proportion formula using Epi info version 7 with a $95 \% \mathrm{CI}, 5 \%$ margin of error, and assumption that $22 \%$ of pregnant women are anemic [16]. Assuming a $10 \%$ nonresponse rate and a design effect of 2, a total sample size of 581 pregnant women was required. Multistage sampling technique was used to select the study participants. Four kebeles (villages) were selected from 6 kebeles using the randomized method. A proportional allocation was employed to obtain the sample size from each kebele. The starting point was randomly selected and a systematic random sampling method was used to select the study participants.

2.4. Data Collection. Data were collected using pretested interviewer administered questionnaire, which contains sociodemographic characteristics (age, education, occupation, marital status, and others), obstetric and gynecological history (trimester, gravidity, parity, ANC follow up, iron supplementation, and others), and dietary factors (type of stable diet, meal frequency, and intake of meat, tea, egg, and milk and milk products).

Blood hemoglobin concentration was measured using a HemoCue $\mathrm{Hb}$ 301, a precalibrated instrument designed for the measurement of hemoglobin concentration. Venous blood was drawn, through microcuvettes, and inserted into the HemoCue and the result was recorded. Mid upper arm circumference (MUAC) of the mothers was measured and recorded as an independent variable.

2.5. Data Processing and Analyses. Data were analyzed using SPSS version 20. Description of means, frequencies, proportions, and rates of the given data for each variable was calculated. Bivariate analysis was done to see the association of each independent variable with the outcome variable. Those variables having $P$ value less than 0.2 were entered into the multivariate logistic regression model to identify the effect of each independent variable with the outcome variables. A $P$ value of less than 0.05 was considered statistically significant, and adjusted odds ratio with 95\% CI was calculated to determine association.

2.6. Ethical Consideration. Ethical clearance was obtained from the Institutional Review Board of the University of Gondar. An official letter was obtained for Somali Regional Health Bureau and Gode City Administration Health Office and letters were prepared for the local authority of the selected kebeles. Written informed consent was obtained from each study participant after they were introduced to the purpose of the study and informed about their rights to interrupt the interview at any time. Confidentiality was maintained at all levels of the study. Mothers found to be anemic were referred to the nearest health center or hospital and the referral process was facilitated.

\section{Results}

3.1. Socioeconomic and Demographic Characteristics. Out of a total sample size (581) 577 pregnant women were included and there was a nonresponse rate of $0.7 \%$. The mean ages of the mothers at present, at marriage, and at first pregnancy were $27.01( \pm 5.97), 17.52( \pm 2.10)$, and $18.38( \pm 2.32)$ years, respectively. Majority of the mothers were married (97.2\%), Somali (98.9\%), and Muslim (99.1\%).

The average family size, number of pregnancies, deliveries, and children of the households were $6.9( \pm 2.86), 4.98$ $( \pm 2.62), 3.83( \pm 2.55)$, and $3.61( \pm 2.38)$, respectively. About 261 $(45.2 \%)$ of the mothers were in their second trimester, 247 $(24.8 \%)$ were in the third trimester, and the remaining 69 $(12.0 \%)$ were in the first trimester.

Most of the mothers were illiterate 507 (87.9\%) and housewives 499 (86.5\%). The family's main sources of income were salaried jobs 301 (52.2\%), private business 101 (17.5\%), and remittance $52(9 \%)$. More than half of the respondents $355(61.5 \%)$ were at or below the middle wealth quintile (Table 1).

3.2. History of Malaria and Intestinal Parasite. Of the 577 respondents, $88(15.3 \%)$ had a known history of intestinal parasite, $548(95.0 \%)$ said they were using insecticide treated bed net (ITNs), and 366 (63.4\%) had a known history of malaria. Of those with a known history of intestinal parasite 7 (8\%) were infected during the current pregnancy, 39 (44.3\%) were infected 1-3 months before the current pregnancy, and the remaining $42(47.8 \%)$ were infected more than four months prior to the current pregnancy. Similarly, from those with known history of malaria $37(10.1 \%)$ were infected during the current pregnancy, 131 (35.8\%) were infected 13 months before current pregnancy, and the remaining 198 (54.1\%) were infected more than four months before current pregnancy.

3.3. Environmental and Housing Characteristics of the Study Subjects. Of the 577 respondents 211 (36.6\%) were living in a rented house, and the remaining 366 (63.4\%) owned the house. Four hundred fifty one $(78.2 \%)$ had private latrine, but only $26(4.5 \%)$ had piped water. Only 18 (3.1\%) had tap water, and only $2(0.3 \%)$ had public tap water as their main source of drinking water. Half (56.5\%) of the study participants obtained drinking water from a protected well/tanker and the remaining 231 (40\%) drank water from arriver. Also, only 34 (5.9\%) of the respondents had a farm or garden to cultivate and assist them in meeting their nutritional needs.

3.4. Behavioral Characteristics and Nutritional Status of Respondents. The most reported staple diet of the household was rice and spaghetti 504 (87.3\%). More than half, 382 (66.2\%), of the respondents eat three times per day.

The majority of the respondents $570(98.8 \%)$ said they drink tea and $444(77.9 \%)$ of them drink tea before meals, and $339(59.5 \%)$ of them have tea more than two times per day. Five hundred fifty four (96\%) and 384 (66.6\%) had eaten meat and used fruits more than twice per week, respectively. 
TABLE 1: Sociodemographic characteristics of pregnant women at Gode town, Somali Region, Eastern Ethiopia, May 2013.

\begin{tabular}{|c|c|}
\hline Variables & $\begin{array}{c}\text { Frequency }(N=577) \\
\text { Number }(\%)\end{array}$ \\
\hline \multicolumn{2}{|l|}{ Age of the mother } \\
\hline$\leq 20$ & $62(10.7)$ \\
\hline $21-25$ & $137(23.7)$ \\
\hline $26-30$ & $187(32.4)$ \\
\hline $31-35$ & $122(21.1)$ \\
\hline$>35$ & $69(12.0)$ \\
\hline \multicolumn{2}{|l|}{ Marital status } \\
\hline Married & $561(97.2)$ \\
\hline Divorced & $13(2.3)$ \\
\hline Widowed & $3(0.5)$ \\
\hline \multicolumn{2}{|l|}{ Religion } \\
\hline Muslim & $572(99.1)$ \\
\hline Christian & $5(0.9)$ \\
\hline \multicolumn{2}{|l|}{ Ethnicity } \\
\hline Somali & $570(98.8)$ \\
\hline Amhara & $5(0.9)$ \\
\hline Oromo & $1(0.2)$ \\
\hline Others & $1(0.2)$ \\
\hline \multicolumn{2}{|l|}{ Educational status } \\
\hline Unable to read and write & $476(82.5)$ \\
\hline Read and write only & $31(5.4)$ \\
\hline Primary school (1-8) & $37(6.4)$ \\
\hline Secondary school & $8(1.4)$ \\
\hline College and above & $25(4.3)$ \\
\hline \multicolumn{2}{|l|}{ Occupation } \\
\hline Housewife & $499(86.5)$ \\
\hline Government employee & $34(5.9)$ \\
\hline Business & $44(7.6)$ \\
\hline \multicolumn{2}{|l|}{ Family Size } \\
\hline$<5$ & $134(23.2)$ \\
\hline $5-7$ & $211(36.6)$ \\
\hline$\geq 8$ & $232(40.2)$ \\
\hline \multicolumn{2}{|l|}{ Age at marriage } \\
\hline$<16$ & $198(34.3)$ \\
\hline $16-18$ & $283(49.0)$ \\
\hline$\geq 19$ & $96(16.6)$ \\
\hline \multicolumn{2}{|l|}{ Source of income } \\
\hline Salary & $301(52.2)$ \\
\hline Business & $101(17.5)$ \\
\hline Remittance & $52(9.0)$ \\
\hline Others & $123(21.3)$ \\
\hline \multicolumn{2}{|l|}{ Wealth index (Quintiles) } \\
\hline Lowest & $114(19.8)$ \\
\hline Second & $127(22.0)$ \\
\hline Middle & $114(19.8)$ \\
\hline Fourth & $104(18.0)$ \\
\hline Highest & $118(20.5)$ \\
\hline
\end{tabular}

More than half of the respondents, $348(60.3 \%)$, said they use egg less than once per month, but 312 (54.1\%) use milk and milk products daily, and $416(72.1 \%)$ had eaten between 5 and 8 food groups in the last 24 hours prior to the interview.
Of the 577 respondents 177 (30.7\%) reported involvement in physical work with $27(15.3 \%)$ and 30 (16.9\%) of them reporting very heavy and heavy physical work, respectively. One hundred seven (18.5\%) reported consuming forbidden foods and 196 (34\%) have reported eating charcoal or clay during pregnancy. More than half of 347 (60.1\%) said they had visited a health facility for antenatal care (ANC) with 56 (16.1\%), 116 (33.4\%), and 175 (50.4\%) of them reporting an initial ANC visit, a second ANC visit, and more than two ANC visits during a pregnancy. More than half of 388 (67.2\%) reported receiving iron supplementation during the current pregnancy.

Nutritional status was evaluated by MUAC and 575 of the respondents were measured (excluding 2 with incomplete MUAC), and 29 (5\%) had MUAC of less than $21 \mathrm{~cm}, 228$ (39.7\%) had MUAC between 21 and $23 \mathrm{~cm}$, and the remaining $318(55.3 \%)$ had an MUAC within normal limits $(>23 \mathrm{~cm})$ (Table 2).

3.5. Prevalence of Anemia. From the total 577 respondents 328 (56.8\%) were anemic (95\% CI: 52.9-60.8), 7 (1.2\%) of them were severely anemic, $154(26.7 \%)$ were moderately anemic, and 167 (28.9\%) were mildly anemic. The mean hemoglobin level was $10.79( \pm 1.47) \mathrm{g} / \mathrm{dL}$. More than half (76.8\%) of the anemic study participants were from large families ( $>5$ family members). Most of them (80.7\%) were multiparous $(\geq 2)$ and multigravidous $(\geq 3)$. Majorities were married at age 18 years or younger $(82.9 \%)$. Most of them $(58.5 \%)$ were at or below the middle wealth quintile and were illiterate (89.9\%).

3.6. Factors Associated with Anemia. Multivariate logistic regression analysis revealed that trimester of current pregnancy, iron supplementation during pregnancy, wealth quintile, number of pregnancies, and MUAC were significantly associated with anemia in the study population (Table 4 ).

Pregnant women in the third and second trimesters were 3.32 (95\% CI 1.84-6.0) and 2.87 (95\% CI 1.61-5.17) times more likely to be affected by anemia as compared to pregnant women in the first trimester, respectively. Similarly, those pregnant women who had 3-5 pregnancies were 1.95 times more likely to be anemic, compared with those who had less than 3 pregnancies ( $\mathrm{AOR}=1.95$ (95\% CI=1.19-3.19)).

Pregnant women who were not taking iron supplementation during pregnancy were 1.54 more likely to develop anemia $(\mathrm{AOR}=1.54(95 \% \mathrm{CI}=1.04-2.27))$.

Pregnant women in the second wealth quintile were $57 \%$ ( $\mathrm{AOR}=0.43,95 \% \mathrm{CI}: 0.24-0.76)$ less likely to develop anemia, compared with those in the lowest wealth quintile. Similarly, pregnant women with MUAC $\geq 23$ were $59 \%$ less likely to be anemic compared with those with $\mathrm{MUAC}<23$ (AOR $=0.41$ (95\% CI: 0.27-0.63)) (Table 3).

\section{Discussion}

More than half $(56.8 \%)$ of the pregnant women studied were anemic. This figure is lower than the prevalence of anemia in 
TABLE 2: Maternal characteristics of pregnant women at Gode Town, Somali Region, Eastern Ethiopia, May 2013.

\begin{tabular}{|c|c|}
\hline Variables & $\begin{array}{c}\text { Frequency }(N=577) \\
\text { Number }(\%)\end{array}$ \\
\hline \multicolumn{2}{|l|}{ Trimester } \\
\hline First trimester & $69(12.0)$ \\
\hline Second trimester & $261(45.2)$ \\
\hline Third trimester & $247(42.8)$ \\
\hline \multicolumn{2}{|c|}{ Age at first pregnancy (years) } \\
\hline$<17$ & $126(21.8)$ \\
\hline $17-19$ & $270(46.8)$ \\
\hline$\geq 20$ & $181(31.4)$ \\
\hline \multicolumn{2}{|c|}{ Number of pregnancies } \\
\hline$<3$ & $166(20.1)$ \\
\hline $3-5$ & $228(39.5)$ \\
\hline$\geq 6$ & $233(40.4)$ \\
\hline \multicolumn{2}{|c|}{ Number of deliveries (parity) } \\
\hline$<2$ & $121(21.0)$ \\
\hline $2-4$ & $237(41.1)$ \\
\hline$\geq 5$ & $219(38)$ \\
\hline \multicolumn{2}{|l|}{ Number of Children } \\
\hline$<2$ & $126(21.8)$ \\
\hline $2-4$ & $247(42.8)$ \\
\hline$\geq 5$ & $204(35.4)$ \\
\hline \multicolumn{2}{|l|}{ Child spacing } \\
\hline Yes & $42(7.3)$ \\
\hline No & $535(92.7)$ \\
\hline \multicolumn{2}{|l|}{ Antenatal care } \\
\hline Yes & $347(60.1)$ \\
\hline No & $230(39.9)$ \\
\hline \multicolumn{2}{|c|}{ ANC during current pregnancy $(n=347)$} \\
\hline Yes & $322(92.8)$ \\
\hline No & $25(7.2)$ \\
\hline \multicolumn{2}{|c|}{ Frequency of ANC (347) } \\
\hline First ANC & $56(16.1)$ \\
\hline Second ANC & $116(33.4)$ \\
\hline Third ANC & $175(50.4)$ \\
\hline
\end{tabular}

pregnant women of some other developing countries such as India and Pakistan $[4,15]$. This may be due to the inclusion of more rural villages in the studies from Pakistan and India, which were not included in this study. This finding is much higher than the national prevalence of anemia in pregnant women, which is $22 \%$ [16], and also higher than the prevalence noted from the 2011 Ethiopian Demographic Health Survey (EDHS) report, which found that $30.4 \%$ of
TABLE 3: Dietary habits and nutritional status of pregnant women at Gode Town, Somali Region, Eastern Ethiopia, May 2013.

\begin{tabular}{|c|c|}
\hline Variables & $\begin{array}{c}\text { Frequency }(N=577) \\
\text { Number }(\%)\end{array}$ \\
\hline \multicolumn{2}{|l|}{ Stable diet } \\
\hline Rice and spaghetti & $504(87.3)$ \\
\hline Maize and sorghum & $68(11.8)$ \\
\hline Others & $5(0.9)$ \\
\hline \multicolumn{2}{|l|}{ Meal frequency } \\
\hline More than three times & $120(20.8)$ \\
\hline Three times & $382(66.2)$ \\
\hline Two times & $63(10.9)$ \\
\hline One time & $12(2.1)$ \\
\hline \multicolumn{2}{|l|}{ Meat frequency } \\
\hline One a week & $137(23.7)$ \\
\hline Twice a week & $267(46.3)$ \\
\hline More than twice per week & $150(26)$ \\
\hline Once per month & $7(1.2)$ \\
\hline Less than one time per month & $16(2.8)$ \\
\hline \multicolumn{2}{|l|}{ Drinking tea } \\
\hline Yes & $570(98.8)$ \\
\hline No & $7(1.2)$ \\
\hline \multicolumn{2}{|l|}{ Time for drinking tea $(N=570)$} \\
\hline Before meal & $444(77.9)$ \\
\hline After Meal & $126(22.1)$ \\
\hline \multicolumn{2}{|l|}{ Fruit frequency } \\
\hline Every day & $28(4.9)$ \\
\hline Once a week & $67(11.6)$ \\
\hline Twice a week & $178(30.8)$ \\
\hline More than twice per week & $111(19.2)$ \\
\hline Once per month & $70(12.1)$ \\
\hline Less than once per month & $348(60.3)$ \\
\hline \multicolumn{2}{|l|}{ Egg frequency } \\
\hline Every day & $25(4.3)$ \\
\hline Once a week & $65(11.3)$ \\
\hline Twice a week & $48(8.3)$ \\
\hline More than twice per week & $21(3.6)$ \\
\hline Once per month & $70(12.1)$ \\
\hline Less than once per month & $348(60.3)$ \\
\hline \multicolumn{2}{|l|}{ Milk and milk product frequency } \\
\hline More than two times per day & $312(54.1)$ \\
\hline Once per day & $160(27.7)$ \\
\hline Once per week & $43(7.5)$ \\
\hline Less than once per week & $62(10.7)$ \\
\hline \multicolumn{2}{|l|}{ Food groups eaten in 24 hours } \\
\hline $1-4$ & $141(24.4)$ \\
\hline $5-8$ & $416(72.1)$ \\
\hline$>8$ food groups & $20(3.5)$ \\
\hline \multicolumn{2}{|l|}{ Physical work } \\
\hline Yes & $177(30.7)$ \\
\hline No & $400(69.3)$ \\
\hline \multicolumn{2}{|l|}{ Forbidden foods for pregnancy } \\
\hline Yes & $107(18.5)$ \\
\hline No & $470(81.5)$ \\
\hline
\end{tabular}


TABLE 3: Continued.

\begin{tabular}{lc}
\hline Variables & $\begin{array}{c}\text { Frequency }(N=577) \\
\text { Number }(\%)\end{array}$ \\
\hline Eating charcoal and clay & $196(34)$ \\
$\quad$ Yes & $381(66)$ \\
$\quad$ No & \\
Iron supplementation & $388(67.2)$ \\
$\quad$ Yes & $189(32.8)$ \\
No & \\
Nutritional status (MUAC) $(n=575)$ & $29(5)$ \\
$<21 \mathrm{~cm}$ & $228(39.7)$ \\
$21-23 \mathrm{~cm}$ & $318(55.3)$ \\
$>23 \mathrm{~cm}$ &
\end{tabular}

Ethiopians were anemic [8]. This discrepancy could be due to the exclusion of agropastoralist zones and the time gap between the current study and the 2011 EDHS.

Gravidity and age of current pregnancy (trimester) were important variables, which have shown a significant association with anemia in the current study. The risk of developing anemia increases with the age of pregnancy (trimester). The risk of developing anemia was higher in third and second trimester when compared with those in the first trimester. This finding is consistent with a study done in Saudi Arabia, which found that the prevalence of anemia is higher in the third trimester in comparison with first trimester [11], and another study conducted in India, which also indicated that the prevalence of anemia was higher in pregnant women in the third and second trimesters [10]. Additionally, studies conducted in Malaysia, Vietnam, and Nepal found that increased gestational age is significantly associated with the risk of developing anemia $[6,17,18]$. This could be due to the fact that when the gestational age increases the mother becomes weak and the iron in the blood is shared with the fetus in the womb therefore decreasing the iron binding capacity of the mother's blood.

The other important variable significantly associated with anemia is number of pregnancies (gravidity). The risk of developing anemia in pregnant women with 3-5 pregnancies is increased when compared with those who had less than 3 pregnancies. This finding is consistent with studies conducted in Saudi Arabia and India, which found that increased number of pregnancies and deliveries is positively associated with the risk of developing anemia $[10,11]$. This could be due to the loss of iron and other nutrients during increased and repeated pregnancies and also the possibility of sharing of resources with the fetus. However, other studies conducted in Ethiopia and Nepal did not find association between gravidity and anemia $[8,18]$. This could be due to the difference in sociocultural characteristics of the study populations.

Similarly the wealth status of the household was significantly associated with the development of anemia. Increased wealth quintiles from lowest to second lowest reduce the risk of developing anemia by $57 \%$. This finding is consistent with the findings from other studies in low and middleincome countries, which found that the risk of anemia among women living in the lowest wealth quintile was increased when compared with those living in the fourth and fifth wealth quintiles. A study done in India showed that pregnant women from lower socioeconomic classes were at increased risk of developing anemia compared with those in higher socioeconomic classes $[2,10]$. This could be due to the fact that those from lower socioeconomic status (SES) lack the ability to purchase the quality or quantity of foods compared with those from higher SES.

Many other studies on anemia in pregnancy conducted in Ethiopia, Pakistan, Nepal, Vietnam, and Malaysia [5, 6, $8,17,18$ ] did not consider the effect of wealth index. This could be because the wealth index is calculated from different household assets.

Two other variables with significant association with anemia were iron supplementation during pregnancy and MUAC level. The risk of developing anemia increased in pregnant women who did not receive iron supplementation during pregnancy when compared with those who received iron supplementation. This finding is consistent with the findings from studies in Vietnam and India, which indicated that lack of iron supplementation is among the most significant risk factors for developing anemia during pregnancy $[6,10]$. This is likely due to the fact that the requirement of iron increases for pregnant women compared with nonpregnant women, and if they do not receive iron supplementation, the iron they ingest from food sources is not adequate to meet their needs. The finding contrasts with a study done at Pakistan, which found that women who reported consuming iron supplementation had a significantly lower hemoglobin concentration. This may be due to a difference in methodology between the studies.

MUAC less than 23 is found to increase the risk of developing anemia. The current study has shown that pregnant women with MUAC $\geq 23$ had 59\% less risk of developing anemia. This finding is consistent with a study done in Nepal, which found that MUAC > 23.6 significantly decreased risk of developing anemia [18]. This can be explained by the fact that undernourished pregnant women have a higher probability of being micronutrient deficient and therefore iron deficient and anemic.

Other independent variables which are not significant factors in this study but found to be significant by other studies reviewed include age of the mother, age at pregnancy, age at marriage, number of deliveries, number of children, family size, educational status of the mother, and occupation of the mother $[5,9,14]$. This could be due to the difference between sociocultural and behavioral characteristics of the community in this study and previous studies.

This study was conducted at the community level and considered altitude as an independent variable to assess anemia. Limitations include the cross-sectional nature of the study and using patient report rather than laboratory data for the identification of previous malarial and parasitic infections. Also, the study did not include rural residents. 
TABLE 4: Factors associated with anemia among pregnant women in Gode town, Somali Region, Eastern Ethiopia; May 2013.

\begin{tabular}{|c|c|c|c|c|}
\hline \multirow{2}{*}{ Variables } & \multicolumn{2}{|c|}{ Anemia status } & \multirow{2}{*}{ COR $(95 \% \mathrm{CI})$} & \multirow{2}{*}{ AOR (95\% CI) } \\
\hline & Anemic & Normal & & \\
\hline \multicolumn{5}{|l|}{ Trimester } \\
\hline First trimester & 24 & 45 & 1.00 & 1.00 \\
\hline Second trimester & 155 & 106 & $2.74(1.58-4.77)$ & $2.87(1.61-5.17)$ \\
\hline Third trimester & 149 & 98 & $2.85(1.63-4.98)$ & $3.32(1.84-6.00)$ \\
\hline \multicolumn{5}{|l|}{ Parity } \\
\hline$<2$ & 63 & 58 & 1.00 & \\
\hline $2-4$ & 150 & 87 & $1.59(1.02-2.47)$ & \\
\hline$\geq 5$ & 115 & 104 & $1.02(0.65-1.59)$ & \\
\hline \multicolumn{5}{|l|}{ Family size } \\
\hline$<5$ & 76 & 58 & 1.00 & \\
\hline $5-7$ & 135 & 76 & $1.29(0.84-1.98)$ & \\
\hline$\geq 8$ & 117 & 115 & $1.75(1.19-2.56)$ & \\
\hline \multicolumn{5}{|l|}{ Forbidden foods } \\
\hline Yes & 70 & 37 & 1.00 & \\
\hline No & 258 & 212 & $0.64(0.41-0.99)$ & \\
\hline \multicolumn{5}{|l|}{ ANC } \\
\hline Yes & 184 & 163 & 1.00 & \\
\hline No & 144 & 86 & $0.74(0.52-1.05)$ & \\
\hline \multicolumn{5}{|c|}{ Iron supplementation during pregnancy } \\
\hline Yes & 207 & 181 & 1.00 & 1.00 \\
\hline No & 121 & 68 & $0.72(0.45-1.15)$ & $1.54(1.04-2.27)$ \\
\hline \multicolumn{5}{|c|}{$24 \mathrm{hr}$ recall food groups } \\
\hline $1-4$ & 94 & 47 & 1.00 & \\
\hline $5-8$ & 224 & 192 & $0.58(0.39-0.87)$ & \\
\hline$>8$ & 10 & 10 & $0.50(0.2-1.29)$ & \\
\hline \multicolumn{5}{|l|}{ Wealth index } \\
\hline Lowest & 49 & 65 & 1.00 & 1.00 \\
\hline Second & 78 & 49 & $0.40(0.24-0.68)$ & $0.43(0.24-0.76)$ \\
\hline Middle & 65 & 49 & $0.85(0.50-1.43)$ & $0.989(0.57-1.72)$ \\
\hline Fourth & 59 & 45 & $0.71(0.42-1.20)$ & $0.69(0.39-1.21)$ \\
\hline Highest & 77 & 41 & $0.70(0.41-1.20)$ & $0.67(0.37-1.19)$ \\
\hline \multicolumn{5}{|l|}{ Gravidity } \\
\hline$<3$ & 59 & 57 & 1.00 & 1.00 \\
\hline $3-5$ & 148 & 80 & $1.79(1.14-2.82)$ & $1.95(1.19-3.19)$ \\
\hline$\geq 6$ & 121 & 112 & $1.04(0.67-1.63)$ & $1.14(0.7-1.85)$ \\
\hline \multicolumn{5}{|l|}{ MUAC } \\
\hline$<23$ & 107 & 44 & 1.00 & 1.00 \\
\hline$\geq 23$ & 219 & 205 & $0.44(0.30-0.66)$ & $0.41(0.27-0.63)$ \\
\hline
\end{tabular}

\section{Conclusion}

The prevalence of anemia among pregnant women in this study was high compared with women in other areas of Ethiopia. Trimester of current pregnancy, wealth quintile, gravidity, iron supplementation, and MUAC were found to be significantly associated with anemia. Iron supplementation and special care during late pregnancy are recommended to reduce anemia. Further research on risk factors of anemia, which include rural residents, should be conducted to strengthen and broaden these findings.

\section{Conflict of Interests}

The authors declare that there is no conflict of interests regarding the publication of this paper.

\section{Authors' Contribution}

Kefyalew Addis Alene and Abdulahi Mohamed Dohe participated in all steps of the study from its commencement to writing it up. They have reviewed and approved the 
submission of the paper. These authors contributed equally to this work.

\section{References}

[1] WHO/CDC, Worldwide Prevalence of Anemia 1993-2005: WHO Global Database on Anemia, WHO Press, Geneva, Switzerland, 2008.

[2] Y. Balarajan, U. Ramakrishnan, E. Özaltin, A. H. Shankar, and S. V. Subramanian, "Anaemia in low-income and middle-income countries," The Lancet, vol. 378, no. 9809, pp. 2123-2135, 2011.

[3] S. Salhan, V. Tripathi, R. Singh, and H. S. Gaikwad, "Evaluation of hematological parameters in partial exchange and packed cell transfusion in treatment of severe anemia in pregnancy," Anemia, vol. 2012, Article ID 608658, 7 pages, 2012.

[4] B. Esmat, R. Mohammad, S. Behnam et al., "Prevalence of iron deficiency anemia among iranian pregnant women; a systematic review and meta-analysis," Journal of Reproduction and Infertility, vol. 11, no. 1, pp. 17-24, 2010.

[5] N. Baig-Ansari, S. H. Badruddin, R. Karmaliani et al., "Anemia prevalence and risk factors in pregnant women in an urban area of Pakistan," Food and Nutrition Bulletin, vol. 29, no. 2, pp. 132139, 2008.

[6] R. Aikawa, N. C. Khan, S. Sasaki, and C. W. Binns, "Risk factors for iron-deficiency anaemia among pregnant women living in rural Vietnam," Public Health Nutrition, vol. 9, no. 4, pp. 443448, 2006.

[7] A. A. Khalafallah and A. E. Dennis, "Iron deficiency anaemia in pregnancy and postpartum: pathophysiology and effect of oral versus intravenous iron therapy," Journal of Pregnancy, vol. 2012, Article ID 630519, 10 pages, 2012.

[8] J. Haidar, "Prevalence of anaemia, deficiencies of iron and folic acid and their determinants in ethiopian women," Journal of Health, Population and Nutrition, vol. 28, no. 4, pp. 359-368, 2010.

[9] M. Akhtar and I. Hassan, "Severe Anemia during late pregnancy," Case Reports in Obstetrics and Gynecology, vol. 2012, Article ID 485452, 3 pages, 2012.

[10] R. G. Vivek, A. B. Halappanavar, P. R. Vivek, S. B. Halki, V. S. Maled, and P. S. Deshpande, "Prevalence of Anemia and its epidemiological," Determinants in Pregnant Women, vol. 5, no. 3, pp. 216-223, 2012.

[11] S. S. Elzahrani, "Prevalence of iron deficiency anemia among pregnant women attending antenatal clinics at Al-Hada Hospital," Canadian Journal on Medicine, vol. 3, no. 1, pp. 10-14, 2012.

[12] N. Raza, I. Sarwar, B. Munazza, M. Ayub, and M. Suleman, "Assessment of iron deficiency in pregnant women by determining iron status," Journal of Ayub Medical College Abbottabad, vol. 23, no. 2, pp. 36-40, 2011.

[13] S. Brooker, P. J. Hotez, and D. A. P. Bundy, "Hookworm-related anaemia among pregnant women: a systematic review," PLoS Neglected Tropical Diseases, vol. 2, no. 9, article e291, 2008.

[14] S. J. Baker and E. M. DeMaeyer, "Nutritional anemia: Its understanding and control with special reference to the work of the world health organization," American Journal of Clinical Nutrition, vol. 32, no. 2, pp. 368-417, 1979.

[15] G. S. Toteja, P. Singh, B. S. Dhillon et al., "Prevalence of anemia among pregnant women and adolescent girls in 16 districts of India," Food and Nutrition Bulletin, vol. 27, no. 4, pp. 311-315, 2006.
[16] Ethiopia, Demographic and Health Survey, Central Statistics Agency, Addis Ababa, Ethiopia, 2011.

[17] Federal Democratic Republic of Ethiopia Population Census Commission, The 2007 Population and Housing census of Ethiopia Results for Somali Region Statistical Report, Central Statistical Agency, Addis Ababa, Ethiopia, 2010.

[18] Z. Makhoul, D. Taren, B. Duncan et al., "Risk factors associated with anemia, iron deficiency and iron deficiency anemia in rural Nepali pregnant women," Southeast Asian Journal of Tropical Medicine and Public Health, vol. 43, no. 3, pp. 735-745, 2012. 


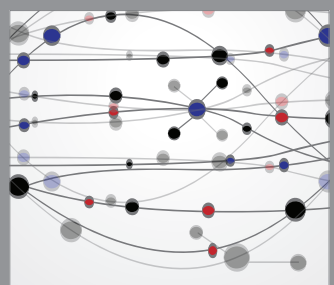

The Scientific World Journal
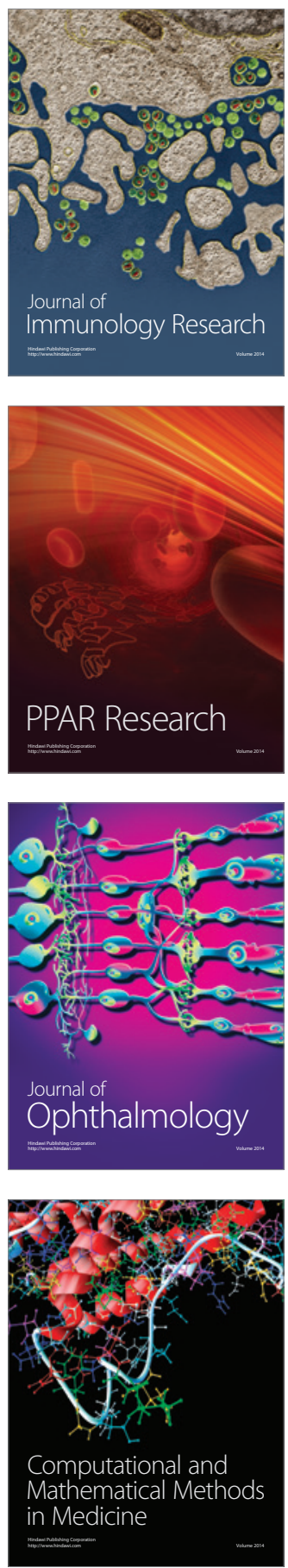

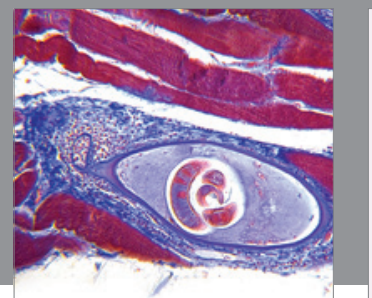

Gastroenterology

Research and Practice
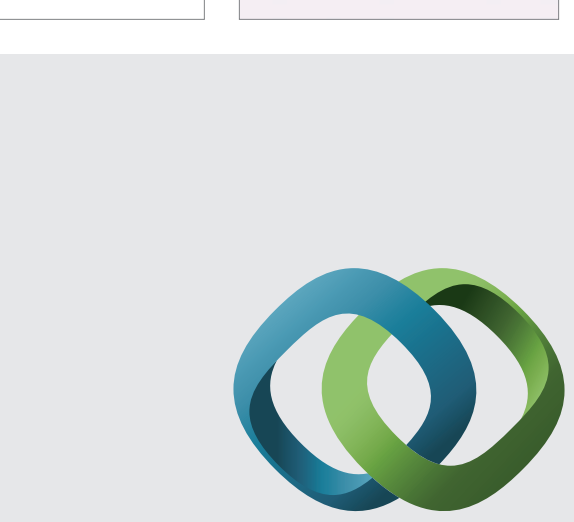

\section{Hindawi}

Submit your manuscripts at

http://www.hindawi.com
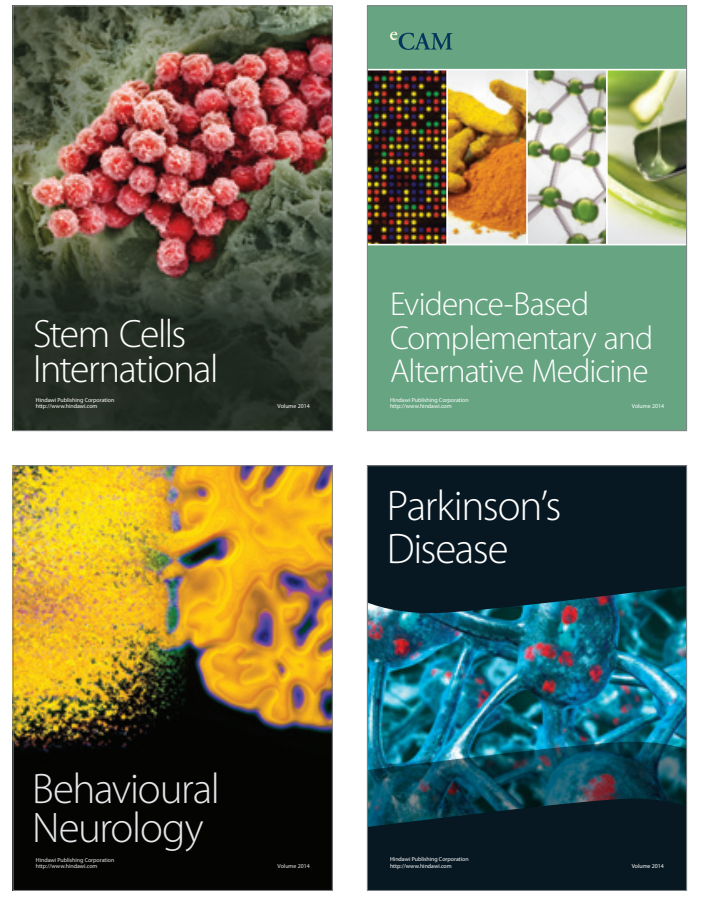
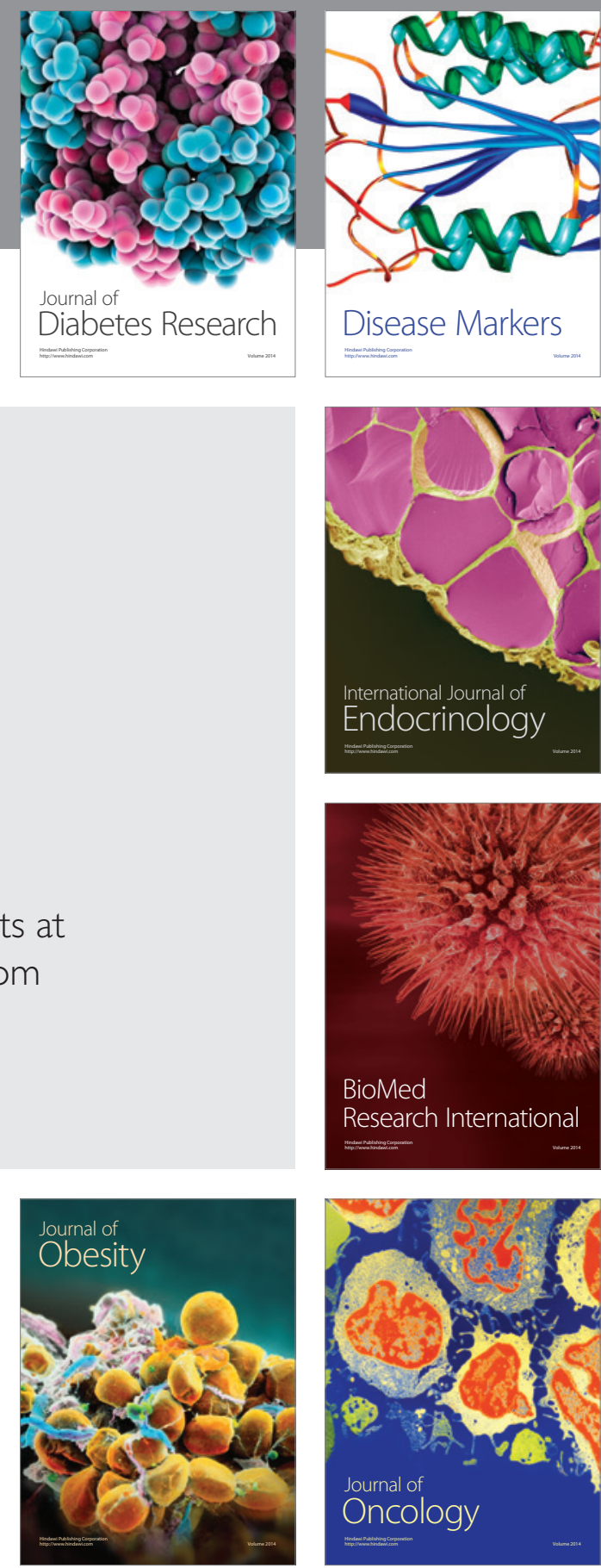

Disease Markers
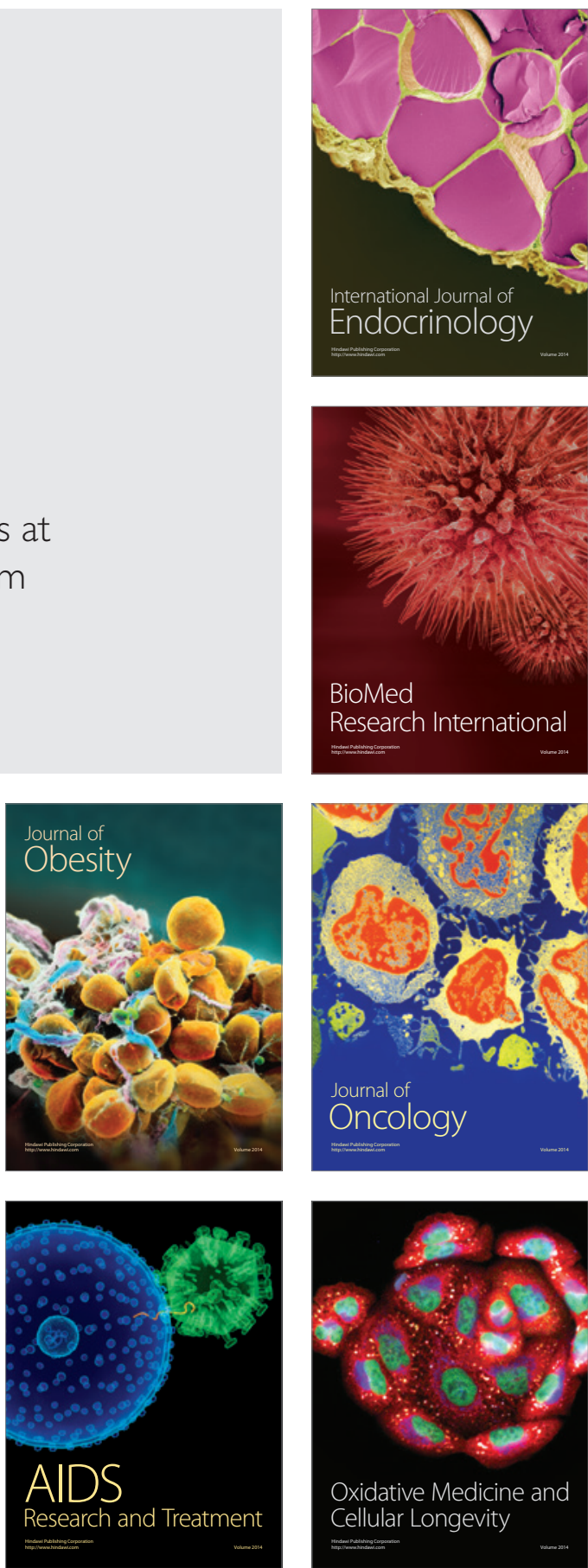